pag

Business School

WORKING PAPER SERIES

Working Paper

$2014-437$

\section{Business Cycle (De)Synchronization in} the Aftermath of the Global Financial Crisis: Implications for the Euro Area

Stelios Bekiros

Duc Khuong Nguyen

Gazi Salah Uddin

Bo Sjö

http://www.ipag.fr/fr/accueil/la-recherche/publications-WP.html

IPAG Business School

184, Boulevard Saint-Germain

75006 Paris

France 


\title{
BUSINESS CYCLE (DE)SYNCHRONIZATION IN THE AFTERMATH OF THE GLOBAL FINANCIAL CRISIS: IMPLICATIONS FOR THE EURO AREA
}

\author{
Stelios Bekiros $^{\mathrm{a}, \mathrm{b}, \mathrm{c}, 1}$, Duc Khuong Nguyen ${ }^{\mathrm{a}}$, Gazi Salah Uddin ${ }^{\mathrm{d}}$, Bo Sjö ${ }^{\mathrm{d}}$ \\ ${ }^{a}$ IPAG Business School, France 184 Boulevard Saint-Germain, 75006 Paris, France \\ ${ }^{\mathrm{b}}$ European University Institute, Department of Economics, Via della Piazzuola 43, I-50133 Florence, Italy \\ ${ }^{c}$ Athens University of Economics and Business, Department of Finance, 76 Patission str, GR104 34, Athens, Greece \\ ${ }^{\mathrm{d}}$ Linköping University, Department of Management and Engineering, SE-581 83 Linköping, Sweden
}

This version: May 18, 2014

\begin{abstract}
The introduction of Euro currency was a game-changing event intended to induce convergence of Eurozone business cycles on the basis of greater monetary and fiscal integration. The benefit of participating into a common currency area exceeds the cost of losing autonomy in national monetary policy only in case of cycle co-movement. However, synchronization was put back mainly due to country-specific differences and asymmetries in terms of trade and fiscal policies that became profound at the outset of the global financial crisis. As opposed to previous studies that are mostly based on linear correlation or causality modeling, we utilize the cross-wavelet coherence measure to detect and identify the scale-dependent time-varying (de)synchronization effects amongst Eurozone and the broad Euro area business cycles before and after the financial crisis. Our results suggest that the enforcement of an active monetary policy by the ECB during crisis periods could provide an effective stabilization instrument for the entire Euro area. However, as dynamic patterns in the lead-lag relationships of the European economies are revealed, (de)synchronization varies across different frequency bands and time horizons.
\end{abstract}

JEL classification: C22, E32

Keywords: Convergence; wavelet coherence; integration; Eurozone

${ }^{1}$ Corresponding author. Tel.: +30 210 8203453; Fax: +30 2108203453 .

E-mail addresses: stelios.bekiros@eui.eu (Stelios Bekiros), duc.nguyen@ipag.fr (Duc Khuong Nguyen), gazi.salah.uddin@liu.se (Gazi Salah Uddin), bo.sjo@liu.se (Bo Sjö). 


\section{Introduction}

Business cycle convergence is considered an important criterion to assess whether a country is ready to participate into a common currency area. This argument dates back to the work of Frankel and Rose (1998) whereby the authors state that individual countries are more likely to meet optimal currency area conditions such as symmetric responses to economic shocks, once a monetary union is established. Indeed, a monetary union leads to an increased convergence in business cycles as it strengthens trade ties and fiscal integration between member countries. Past studies by Bayoumi and Eichengreen (1997), Masson and Taylor (1993), and Alesina et al. (2002) suggest that the benefit of participating into a common currency area exceeds the cost of losing national autonomous monetary policy only if business cycles co-move closely across countries. In case business cycles diverge, some countries may find it hard to endure a common currency area while experiencing volatile business cycles. The introduction of the Euro currency in 1999 intended to "force" the Eurozone countries' business cycles to converge on the basis of greater economic and fiscal integration. However, this synchronization process was put back mainly due to countryspecific differences in terms of trade and fiscal policies, which in turn caused asymmetric responses by the member countries to global and regional shocks. This asymmetry became profound at the outset of the global financial crisis in 2007 and during the subsequent Eurozone debt crisis.

A plethora of studies exists on business cycle synchronization in Europe, yet providing mixed results. An important stream of empirical work suggests that the degree of synchronization is relatively high, presenting a steady increase over the last 20 to 30 years. Evidence provided in the literature appears to be inconsistent with respect to a commonly accepted definition of synchronization (Artis and Zhang, 1997; Forni et al., 2000; Artis et al., 2004). Moreover, there is a split of opinion on whether i) synchronization has increased for all member states ii) the amplitude (magnitude) and duration of cycles has decreased or not, iii) even whether fixed or floating exchange rates have an asymmetric effect on the degree of synchronization as reported by Bergman (2006). On the contrary, Bordo and Helbing (2011) find that business cycle synchronization among 
industrialized countries has increased over the last century independently of fixed or floating exchange rates. In that perspective, both the European Monetary Union and the introduction of Euro might not have changed the long-run trend towards greater synchronization.

Evidently, a proper measure of business cycle synchronization is of utmost importance in adjusting monetary policy in the Eurozone, particularly under the increasing economic uncertainty and financial stress caused by the recent crises. A crucial issue in measuring business cycle convergence based on time series statistical techniques is that often results can be sensitive to the frequency of the sample utilized. On the other hand results from studies based on the frequency domain are not always easy to be translated back to the time domain, which directly corresponds to lead-lag relationships associated with economic policy making and investment decisions. In our work we propose a compromise between time and frequency domain as implemented by the wavelet analysis. As opposed to previous studies the utilization of the wavelet approach enables to detect time-varying links between counties' economic activity under a time-frequency framework, hence providing insights into potentially changing patterns of business cycle synchronization.

Our approach assumes Germany's growth as the main driver of EU economic activity. We pursue a sensitivity analysis via exploring the synchronization between Germany and Eurozone countries namely Finland, France and Italy, yet in a comparative evaluation with countries that remained outside the common currency area such as Norway, Sweden and the UK. To get an adequately long and informative sample we use monthly data starting in 1993. The selection of the starting point coincides roughly with the ratification of the Maastricht Treaty by the European Union countries, which paved the road towards the establishment of Euro in 1999. The financial crisis of 2007-2009 is examined. It was triggered by a liquidity shortfall in the US banking system, which resulted in the collapse of large financial institutions and turbulence in stock markets around the world. Finally, the EU sovereign debt crisis that was initiated at the end of 2009 is also investigated. To test the effect of the financial crisis on Euro area business cycle synchronization we simply split the data in two samples, i.e., the first one covering the period from January 1993 to 
December 2007, whilst the extended (total) sample includes the financial crisis and spans January 1993 to October 2012. Interestingly, we show that the strength of co-movement of business cycles differs among countries and changes continuously over the investigated time horizon. In the presence of financial crisis, the interdependencies between Germany and the countries inside and outside the Eurozone, present significant time-variation at different frequency bands and at diverse time horizons.

The paper is organized as follows: the next section provides an extensive overview of the European business cycle literature. Section 3 describes the data, while Section 4 presents a new time-scale measure of (a)synchronization based on wavelet methodology. Section 5 reports and discusses the empirical results. Section 6 summarizes the key findings and concludes.

\section{Literature Review}

Many studies have focused on synchronization amplification under fixed exchange rates, such as within a common currency area. Rose and Engel (2002) claim that members of currency unions are more integrated in terms of GDP cycles than individual countries. These findings are challenged by Baxter and Kouparitsas (2005) and Artis et al. (2005) who conclude that European business cycles show signs of quite the opposite, i.e., divergence. The differences between U.S. state and European Union growth co-movements were further examined by Clark and Wincoop (2001) who found that the business cycles among U.S. census regions were substantially more synchronized than those of European countries. Wynne and Koo (2000) compared EU-15 with the Federal districts in the USA and concluded that synchronization in the USA was significantly higher than in Europe. However, after the introduction of Euro the business cycle convergence in the Euro area has been rising according to the same study. Working on European countries and other industrialized economics, Camacho et al. (2006) illustrate that Euro economy is more synchronized compared to the other economics. Applying a rolling window approach, Lopes and Pina (2008) compare the evolution of synchronization in Europe with the two other currency unions of Canada 
and USA, utilizing a quite long sample from 1950 to 2005. They conclude on synchronization enhancement amongst EU countries and thus on the viability of the Euro currency.

Other researchers are concerned with the economic reasons for business cycle co-movements and explore the specific factors that explain convergence or desynchronization. Using a panel dataset for 186 countries in the period 1970 - 1990, Rose (2000) finds that currency unions increase trade substantially and concludes that a country is more likely to satisfy the criteria for entry into a currency union ex-post than ex-ante. This implies a share of currency trade three times as much as with different currencies. Consequently, currency unions (e.g., EMU) may lead to a large increase in international trade with all that entails. According to Imbs (2004) more financially integrated countries appear to be more synchronous in economic activity. This means that the co-movement effect is independent of trade or financial policy, but directly reflects differences in GDP per capita. In addition, the results by Inklaar et al. (2008) signify that convergence in monetary and fiscal policies can have a measurable impact on business cycle synchronization. However, evidence on this topic is also inconclusive. For instance, Baxter and Kouparitsas (2005) argue that currency unions are not important determinants of business cycle synchronization - or at least this effect is not consistently robust - whilst Camacho et al. (2008) provide evidence that differences between business cycles in the Euro area have not disappeared after the introduction of Euro.

Comparisons between convergence in the broad Euro area and within the Eurozone are extensive. Fidrmuc and Korhonen (2006) and Forni et al. (2000) investigate the European economic activity with the application of a dynamic factor model in order to extract the common European Activity Index. In the same vein, however via a different approach Artis et al. (2004) implement Markov-switching VAR modelling to examine a common unobserved component that might determine the dynamics of a European-wide business cycle. Overall, the findings from these and other relevant works on the differences between the Eurozone and the broad EU area are largely inconclusive. During the period 1993-1997 Angeloni and Dedola (1999) describe the rise of the output correlation between Germany and the other European countries. They show that cross- 
country correlations both of business cycles and inflation risen significantly in recent years among EMU participants and provide the evidence that monetary policy rules followed by central banks have tended to converge. Furthermore, Inklaar and Haan (2001) do not find any evidence of a connection between exchange rate stability and business cycle synchronization in Europe. Crowley (2008) finds that macroeconomic variables evolved in a divergent way within the Euro area and reports the existence of a geographical core-periphery pattern.

Working on the OECD countries Furceri and Karras (2008) investigate whether the business cycles of the EU countries have become more or less synchronized after the introduction of the Euro. They results suggest that the relationship between country size and business cycle volatility is negative and statistically significant. In the same work using data for the period 1993-2004, Furceri and Karras (2008) investigate business cycle synchronization for the EU-12 countries and conclude that they appear more synchronized after joining the Euro. In a sectoral study Afonso and Furceri (2009) using annual data for the EU-27 countries show that in general, Industry, Building and Construction as well as Agriculture generate the highest contribution to aggregate output business cycle synchronization during the period 1980-2005, whilst for Services business cycle convergence is indicatively low.

Finally, Aguiar-C and Soares (2011) using spectral approaches examine synchronization across the EU-15 and the Eurozone countries. Without testing for significance, they claim that France and Germany form the core of the Euro area as they seem most synchronized compared to the rest of Europe. As the starting point of their sample is 1975 M07, i.e., too far away for the Maastricht Treaty (1992) which initiated the introduction of the common currency, Rua (2010) argues that their results cannot be considered consistent even though a robust methodology as wavelets was used. Rua (2010) shows that sample selection is crucial in that the strength of business cycle co-movement using wavelets depends critically on the choice of a pre- or post-Maastricht dataset. In the present study we follow Rua (2010) in terms of sample selection. 


\section{Preliminary analysis}

The dataset employed in our study comprises seasonally adjusted monthly industrial production indices for three Eurozone countries i.e., Germany, France and Finland and three nonEurozone countries namely Norway, Sweden and United Kingdom. The industrial production indices can be considered as proxies for business cycle activity as they measure the supply side of the economy. They are also available at monthly frequency, which allows the utilization of sufficient number of observations in our empirical analysis. The investigated period spans January 1993 to October 2012. The selection of the starting point (1993M1) coincides roughly with the ratification of the Maastricht Treaty by the European Union countries, which paved the road towards the establishment of the common currency in 1999. The seasonally adjusted monthly industrial production indices are collected from Thompson Datastream International database. In our analysis, we estimate the logarithm of the industrial production indices. As a robustness analysis with respect to the empirical results, aside from the total period (denoted as $\mathrm{P}_{\text {Total }}$ ) we consider the 1993M1-2007M12 sub-sample ( $\left.\mathrm{P}_{\text {pre-crisis }}\right)$ that excludes the 2007 US subprime crisis in an attempt to explore the potential after-effect of the global financial crisis on European business cycle synchronization.

Figure 1 depicts the log-series of monthly industrial production indices for seven European countries, namely Germany, France, Finland, Norway, Sweden and the United Kingdom during the entire period 1993M1-2012M10. Interestingly, the visual representations can be revealing of the differences observed with respect to the impact of the financial crisis on the various countries. The IP indices demonstrate that the financial crisis affected all countries except Norway, in a historically unprecedented way. In particular, Norway's industrial production exhibits a peak around 2004, whilst thereafter it appears to show a steady decline up to 2010. On the other hand, Germany was severely affected by the crisis, yet recovered within two years, as opposed to Finland and Sweden that were both impacted to a less extent and were able to stabilize their output around 2009-2010. Furthermore, France, Italy and the UK presented a strong growth from early 1990s up to 2008s just 
before the financial crisis and the subsequent Euro debt crisis. Indicatively, the industrial production in these countries peaked around 2000 and remained stable until the burst of the global crisis. While they were severely affected by the subprime crisis their industrial production declined further from 2010 onwards mainly due to the consequent debt crisis. Eventually, the robust and sustainable growth in the industrial basis of Germany, Finland and Sweden enabled them to constrain the huge consequences of the two joint crises that affected the other countries severely.

Table 1 presents the descriptive statistics for the examined series. The Finish business cycle is the most volatile as measured by the unconditional standard deviation, in comparison to the other countries. Moreover, the IP indices are negatively skewed for all series, with the exception of Germany, whilst kurtosis is positive for all series and in particular greater than 3 for Italy, Norway and UK during the $\mathrm{P}_{\text {pre-crisis }}$ sub-period. The Jarque-Bera test (JB) corroborates evidence that the series are not normally distributed. The results of the Ljung-Box test on the log-levels for 12-order autocorrelation are significant for both periods, whilst the Engle's ARCH(12) test provides strong evidence of conditional heteroscedasticity. Table 2 reports the Augmented Dickey-Fuller (1981) and the Phillips-Perron (1988) unit root tests. They are applied to examine the stationarity of the seasonally adjusted log-series of industrial production. The tests generate inconclusive results in accordance with Baum (2004) who argues that conventional unit root tests are not reliable in the presence of structural breaks. Hence, we implement the Zivot-Andrews (1992) structural break unit root test. Including various dates to signify structural breaks, the results shows that series before or after the selected dates can be considered near-stationary except for Norway, which yet is found to reject the unit root hypothesis based on the Phillips-Perron test.

Additionally, we report the unconditional correlation matrix amongst the business cycle series in Table 3. Linear correlations seem to be weak for all Eurozone and non-Eurozone pairs vis-à-vis Germany particularly for the total sample (including the crisis period) as opposed to the pre-crisis period. In both periods, unconditional correlation is positively high for the Germany-Sweden pair, followed by the Germany-Finland and Germany-France links. In addition, the unconditional 
correlation between Germany, Norway UK and Italy seems to be rather weak in the pre-crisis period. However, the relationships are vastly modified when both crises are "excluded" from the investigated sample. Overall, the correlation coefficients become positive and large in magnitude, showing evidence of business cycle synchronization. They also indicate the heterogeneity of the crisis impact on each country as well as demonstrate the collapse of market synchronicity during the imminent crises that affected the Euro area.

Nevertheless, it would be interesting to explore the interrelationships across different time periods based on multi-resolution analysis. The continuous wavelet transform can be particularly useful in examining the scale-dependent phase between the examined business cycles in the Euro area. As opposed to the simple linear correlation, the wavelet coherence measure detects linear and nonlinear (or time-varying) phase-dependent linkages via the cross-wavelet power spectrum.

\section{Time-scale measurement of (a)synchronization}

Wavelet analysis allows for the estimation of spectral characteristics and scale-related components of the time series over and across time horizons. We particularly employ the continuous wavelet transform (CWT) to analyze the phase, synchronization and time-varying comovement of business cycles inside and outside the Eurozone. In general, the CWT incorporates three main features: the cross-wavelet power, the cross-wavelet coherency and the phase difference. The cross-wavelet power reveals the scale-dependent covariance between time series, whilst coherency - as the correlation coefficient in time domain - estimates the pairwise interrelationships, yet in the time-frequency domain. Finally, the CWT phase indicates the position in the pseudo-cycle of a series as a function of frequency. Consequently, the phase-difference provides information on the delay, or synchronization between oscillations of the investigated time series (Aguiar-Conraria et al., 2008). In our study, we measure the degree of synchronization between all pairs of business cycles vis-à-vis Germany including France and Finland for Eurozone countries (common Eurocurrency area) as well as three non-Eurozone countries namely Norway, Sweden and United 
Kingdom. As the CWT is particularly useful in detecting the scale-dependent convolution between time-series, we specifically utilize the coherence measure, which enables the identification of phase (synchronization) or the anti-phase (asynchronization) between oscillations of the series under consideration (Aguiar-Conraria and Soares, 2013).

\subsection{Formal description}

The wavelet transform decomposes a time series in terms of a wavelet function $\psi_{\sigma}(t)$ that depends on time $t$. Following Rua and Nunes (2009), we use the continuous Morlet wavelet function $\psi_{\sigma}(t)$ with a frequency parameter that is equal to six. ${ }^{2}$ The continuous wavelet transform $W_{t}^{\Phi}(\Theta)$ of a discrete sequence $x_{m}(m=1, \ldots, M-1, M)$ with uniform time steps $\delta_{t}$ is defined as the convolution of $x_{m}$ with the scaled and normalized wavelet. The equation can be written as

$$
W_{t}^{\Phi}(\Theta)=\sqrt{\frac{\delta_{t}}{r}} \sum_{t=1}^{M} x_{m}, \psi_{\sigma}\left[\frac{\left(m^{\prime}-m\right) \delta_{t}}{r}\right]
$$

where $\delta$ is the time step. The wavelet power as defined by $\left|W_{t}^{\Phi}(\Theta)\right|^{2}$, represents the ratio of the cross power spectrum of two series over the product of each series' power spectrum, and can thus be interpreted as the localized correlation between the series under consideration. Let two countries economic activity series be denoted as $X_{t}$ and $Y_{t}$ and depicted by their industrial production indices (e.g., Germany-France). Assuming that their wavelet power spectra are $W_{t}^{\Phi}(\Theta)$ and $W_{t}^{\Gamma}(\Theta)$ respectively, the cross-wavelet power spectrum is provided by $W_{t}^{\Phi \Gamma}(r)=W_{t}^{\Phi}(\Theta) \cdot W_{t}^{\Gamma}(\Theta)$. Consequently, their wavelet coherence measure is computed as

$$
R_{t}^{2}(\Theta)=\frac{\left|Q\left(\Theta^{-1} W_{t}^{\Phi Г}(\Theta)\right)\right|^{2}}{Q\left|\left(\Theta^{-1}\left|W_{t}^{\Phi}(\Theta)\right|^{2}\right)\right| \cdot Q\left|\left(\Theta^{-1}\left|W_{t}^{\Gamma}(\Theta)\right|^{2}\right)\right|}
$$

\footnotetext{
${ }^{2}$ Using different functions does not significantly changes the results in the empirical application.
} 
where Q refers to a smoothing operator (Rua and Nunes, 2009). The numerator in Eq. (2) is the absolute squared value of the smoothed cross-wavelet spectrum, while the denominator represents the smoothed wavelet power spectra (Torrence and Webster, 1999; Rua and Nunes, 2009). The value of the wavelet squared coherence $R_{t}^{2}(\Theta)$ is bounded between 0 and 1 , with a high value showing strong business cycle co-movement. However unlike the standard correlation coefficient, the wavelet coherence measure only takes positive values. The graphical presentation of the wavelet squared coherency enables to identify the "area" of co-movement between the two investigated countries in the time frequency space. As in Torrence and Compo (1998), Monte Carlo simulation methods are used to generate the statistical significance of coherence.

\section{Empirical Findings}

We implement the CWT to examine the scale-dependent phase and time-varying comovement of business cycles inside and outside the Eurozone, with Germany being the focal point of economic activity. In measuring the cross-movements between business cycles, we utilize the continuous wavelet cross-coherence measure in order to identify both frequency bands and time intervals within which pairs of the industrial production log-levels are co-varying.

In Figures 2 and 3 we report contour graphs of the cross-wavelet coherency for the business cycles of Germany vis-à-vis Eurozone countries (i.e., Germany vs. France, Finland and Italy) and Non-Eurozone (Euro area) (i.e., Norway, Sweden and UK) respectively. The left column (Panel A) of sub-plots in each of Figures 2 and 3 depicts the results of the coherence measure for the pre-crisis period $\left(\mathrm{P}_{\text {pre-crisis }}\right)$, while the right column (Panel $\left.\mathrm{B}\right)$ for the expanded total period $\left(\mathrm{P}_{\text {Total }}\right)$, i.e., including the global financial crisis and the Eurozone debt crisis. Thick black contour lines depict the $95 \%$ confidence intervals estimated from Monte Carlo simulations using phase-randomized surrogate series. Frequency (scale) is depicted on the vertical axis and time on the horizontal axis in months. The color code for power ranges from blue - used for low coherency - to red indicating high coherency. The coherency measure incorporates linear and nonlinear interdependencies 
including $2^{\text {nd }}$ or higher order effects, beyond simple linear correlation relationships. The downward pointing "cone of influence" indicates the region affected by the so-called "edge effects" and is shown with a lighter shade black line. The direction of the arrows provides the lag/lead phase relation between the examined series. Arrows pointing to the right signify phase-synchronized series whilst those pointing to the left indicate out-of-phase variables. Arrows pointing to the rightdown or left-up indicate leading business cycles for Germany, while instead right-up or left-down arrows show a lagging cycle for Germany vis-à-vis the other countries. The in-phase regions signify a cyclical interaction between the variables while the out-of-phase or anti-phase behavior demonstrates an anti-cyclical effect. The contour plots (derived by a three-dimensional analysis) enable to detect areas of varying co-movement among return series over time and across frequencies. Overall, the areas of stronger co-movement in the time-frequency domain imply higher synchronization and convergence.

As it can be observed in Figure 2 for the pre-crisis period, Germany and France present a high co-movement within the cone of influence and in particular the business cycle of Germany is leading that of France. The arrows (deep red areas) pointing to the right indicate that the business cycles are in-phase. Specifically, in the frequency band that spans 32-36 months (around 3 years) from 1997 to 2000s, the right-down arrow direction signifies that Germany strongly leads France. In case of the total period (including the crisis) the results show that co-movement between Germany and France acquires a progressively higher degree. In particular, for the whole range of low to high scales (8-64 months or nearly 0.5-5.25 years) within 1995-2010, the deep red area arrows point right in the higher power region within the cone of influence. While in some other points the deep red-areas are directionally right-up and right-down, yet this effect can be safely considered negligible comparing the entire region of high power. In examining the broad Euro area convergence, Germany and Finland demonstrate an in-phase relationship. The business cycle of Finland is leading Germany from 1997 to 2002 (pre-crisis period) at the medium term scale (28-34 months). When both crises are included in the sample, the two aforementioned cycles are in-phase 
and co-move even at the lowest time scale. For the time-frequency interval of 1-3.25 years (or 1240 months) that corresponds to the 1995-2008 period, the arrows (black line) show in general an in phase behaviour, however, in some parts of the state space right-down pointing arrows indicate a leading linkage of the German business cycle versus the Finnish one. Interestingly, the other coherence arrows within the high power spaces acquire a strong right direction, which means that that the economies in question are in a linear phase without consistently preserving any lag or lead relationship. Moreover, the investigated wavelet phase measure for the pair Germany-Italy reveals an in-phase relationship without a distinct lead-lag relationship as shown from the examination of the cone of influence. The results in this case vary, in that most of the red-areas are pointing right only during the pre-crisis period, whilst the Italian business cycle leads the German one at the 32-40 month interval, namely during the 1998-2006 period.

When the non-Eurozone countries are investigated, the results of synchronization are diverse. In Figure 3 the cross-coherence of Germany with Norway, Sweden and United Kingdom is displayed. Interestingly, the contour plot shows that the Germany-Norway business cycle comovement generates no power near the region of cone of influence, i.e., no evident directional causality can be inferred. Furthermore, for the lower to medium term frequency band (18-22 months) around 2000-2001, the arrows direction (left-up) indicates desynchronization, thus anticyclicality. These results on Germany-Norway integration show no important differences between pre- and post crisis periods. Next, the Swedish economic cycle is analyzed. The evidence shows that the two economies are in-phase. Looking at the high power (high correlation) region of the wavelet coherence plot, the high-phase arrows indicate convergence. Specifically, during the 1996-2006 period that relates to the frequency band of 1.5-4 years, most of the red area arrows turn right-up, meaning that the business cycle of Sweden leads that of Germany, with the exception of few arrows pointing right-down in the pre-crisis period. When the financial crisis is accounted for, still the relationship displays phase synchronization with high power, while in particular for the lowest frequency of 20-40 months corresponding to the 1997-2000 period, the Swedish economy leads 
German. Finally, the co-movement between Germany and UK appears to be "concentrated" on the medium term frequency band (typical business cycle scales) in what concerns the pre-crisis period. For example, in the 16-34 months frequency band, the coherence plot signifies a leading business cycle for UK vis-à-vis Germany. These medium scale results relate to the time periods of 19962002 and 2004-2006. Instead, the cycle synchronization between Germany and UK is mostly observed in the low scales when the crisis period is incorporated in the data sample. For the 8-16 and 16-34 month scales namely during 1994-2006 and 2005-2006 respectively, the right-up arrows reveal that UK economy leads the German one. Overall, when the financial crisis is accounted for the interdependencies between Germany vs. Eurozone and Euro area counties are modified, while the convergence and (de)synchronization evidence varies at different frequency bands and time horizons.

\section{Conclusions}

As opposed to previous studies that are mostly based on linear correlation or causality modeling, we utilized the wavelet approach to detect and identify synchronization and convergence amongst Euro area and Eurozone business cycles before and after the financial crisis, considering Germany as the focal point of economic activity. In measuring the cross-movements, we utilize the continuous wavelet cross-coherence measure to explore the scale-dependent time-varying (anti)phase between the examined business cycles in the time-frequency domain.

The results for the Eurozone countries indicated that concerning Finland, the German and Finish business cycles display strong synchronization in the lower scales during the pre- and postfinancial crisis periods. In particular for the pre-crisis period Finland leads the German cycle at midterm frequency bands. Similarly, in the pre-crisis period the German economy strongly leads the French one, whilst in the total period analogous results are corroborated, yet under a more gradual fashion regarding the temporal dimension. In case of Italy, a perfect in-phase relationship showing no lead-lag links is observed within the high power energy zone in the pre-crisis period, whereas 
after the crisis emerges the business cycles are in phase, yet mostly over the medium term scales. Next, for the non-Eurozone countries the results are diverse. Business cycle co-movements between Germany and Sweden show high coherence (dependence) thus convergence in both periods, with Sweden leading Germany. The co-movement between Germany and UK is concentrated at medium-term frequency bands in the pre-financial crisis period. Instead, the cycle synchronization is observed in low scales when the crisis period is included. Lastly, no evident directional causality can be inferred in both periods for the pair Germany-Norway, with the exception of desynchronization and anti-cyclicality at medium term frequency bands during 2000-2001.

In general, Germany appears to be strongly synchronized both with the Eurozone and nonEurozone countries, albeit the degree of co-movement is enhanced across different frequencies and sub-periods during the crisis period. The empirical results confirm that synchronization increases within Euro area whereby the co-movement appears to be accumulated and intensified on the medium term frequency bands (typical business cycle scales) mostly during the financial crisis.

Overall our results suggest that the enforcement of an active monetary policy by the European Central Bank (ECB) due to increased synchronization during crisis periods could provide an effective stabilization instrument for the entire Euro area. However, as dynamic changes in the leadlag relationships of the European economies are observed, convergence and (de)synchronization varies strongly across different frequency bands and time horizons. Hence, it might be more efficient for the ECB to employ optimal policy in a timeless perspective in order to account for time-varying asymmetric co-movements as opposed to simple Ramsey-style policies under commitment. 


\section{References}

Afonso, A., and Furceri, D. 2009. Sectoral Business Cycle Synchronization in the European Union. Economics Bulletin 29(4), 2996-3014.

Aguiar-Conraria, L., Azevedo, N., and Soares, M. J. 2008. Using wavelets to decompose the time-frequency effects of monetary policy. Physica A: Statistical mechanics and its Applications 387(12), 2863-2878.

Aguiar-Conraria, L., and Soares, M. J. 2011. Oil and the macroeconomy: using wavelets to analyze old issues. Empirical Economics 40(3), 645-655.

Aguiar-Conraria, L., and Soares, M. J. 2011. Business cycle synchronization and the Euro: a wavelet analysis. Journal of Macroeconomics 33(3), 477-489.

Angeloni, I., and Dedola, L. 1999. From the ERM to the euro: new evidence on economic and policy convergence among EU countries. ECB Working Paper No. 4.

Artis M., Proietti T., and Marcellino, M. 2005. Business cycles in the new EU member countries and their conformity with the Euro area. Journal of Business Cycle Measurement Analysis $2,7-42$.

Artis, M. J., and Zhang, W. 1997. International business cycles and the ERM: Is there a European business cycle? International Journal of Finance and Economics 2(1), 1-16.

Artis, M., Marcelino, M., and Proietti, T. 2004. Characterizing the Business Cycle for Accession Countries. CEPR Discussion Paper N. 4457.

Baxter, M., and Kouparitsas, M. 2005. Determinants of Business Cycle Co-movement: A Robust Analysis. Journal of Monetary Economics 52, 113-157.

Bergman, U. M. 2006. How Similar are European Business Cycles? in G.L. Mazzi and G. Savio (Eds.), Growth and Cycle in the Euro-zone, Palgrave Macmillan.

Bordo, M. D., and Helbing, T. F. 2011. International Business Cycle Synchronization in historical Perspective. The Manchester School 79(2), 208-238.

Camacho, M., Perez-Quiros, G., and Saiz, L. 2006. Are European business cycles close enough to be just one? Journal of Economic Dynamics and Control 30, 1687-1706.

Camacho, M., Perez-Quiros, G., and Saiz, L. 2008. Do European business cycles look like one? Journal of Economic Dynamics and Control 32, 2165-2190.

Clark, T. E., and Wincoop, E. 2001. Borders and business cycles. Journal of International Economics 55, 59-85.

Crowley, P. 2008. One money, several cycles? Evaluation of European business cycles using model-based cluster analysis. Evaluation of European Business Cycles using Model-Based Cluster Analysis.

Dickey, D. A., Fuller, W. A. 1981. Likelihood ratio statistics for autoregressive time series with a unit root. Econometrica, 1057-1072

Fidrmuc, J., and Korhonen, I. 2006. Meta-analysis of the business cycle correlation between the euro area and the CEECs. Journal of Comparative Economics 34, 518-537.

Forni, M., Hallin, M., Lippi, M. and Reichlin, L. 2000. The Generalized Factor Model: Identification and Estimation. Review of Economics and Statistics 82, 540-554.

Furceri, D., and Karras, G. 2008. Business cycle volatility and country size: evidence for a sample of OECD countries. Economics Bulletin 5(3), 1-7.

Gallegati, M., and Gallegati, M. 2007. Wavelet variance analysis of output in G-7 countries. Studies in Nonlinear Dynamics and Econometrics 11(3), Article 6.

Goupillaud, P., Grossman, A., and Morlet, J. 1984. Cycle-octave and related transforms in seismic signal analysis. Geoexploration 23, 85-102.

Grinsted, A., Moore, J. C., and Jevrejeva, S. 2004. Application of the cross wavelet transform and wavelet coherence to geophysical time series. Nonlinear Processes in Geophysics 11, 561-566.

Harding, D., and Pagan, A. 2006. Synchronization of cycles. Journal of Econometrics 132, $59-79$. 
Hudgins, L. F. C. M. M. 1993. Wavelet transforms and atmospheric turbulence. Physical Review Letters 71 (20), 3279-3282.

Imbs, J. 2004. Trade, finance, specialization, and synchronization. The Review of Economics and Statistics 86, 723-734.

Inklaar, R., Jong-A-Pin, R., and de Haan, J. 2008. Trade and business cycle synchronization in OECD countries--A re-examination. European Economic Review 52, 646-666.

Inklaar, R., and De Haan, J. 2001. Is there really a European business cycle? A comment. Oxford Economic Papers 53(2), 215-220.

De Haan, J., Inklaar, R., and Jong A Pin, R. 2008. Will business cycles in the euro area converge? A critical survey of empirical research. Journal of Economic Surveys 22(2), 234-273.

Ferreira-Lopes, A., and Pina, A. M. 2011. Business Cycles, Core, and Periphery in Monetary Unions: Comparing Europe and North America. Open Economies Review 22(4), 565-592.

Phillips, P. C., Perron, P. 1988. Testing for a unit root in time series regression. Biometrika 75, 335-346.

Ramsey, J., and Lampart, C. 1998a. Decomposition of economic relationships by time scale using wavelets: money and income. Macroeconomic Dynamics 2, 49-71.

Ramsey, J., and Lampart, C. 1998b. The decomposition of economic relationships by time scale using wavelets: expenditure and income. Studies in Nonlinear Dynamics and Econometrics 3, 23-42.

Ramsey, J. B. 2002. Wavelets in economics and finance: past and future. Studies in Nonlinear Dynamics and Econometrics 6(3), Article 1.

Ramsey, J. B. 1999. The contribution of wavelets to the analysis of economic and financial data. Philosophical Transactions of the Royal Society of London Series A 357, 2593-2606.

Rose, A. K. 2000. One money, one market: estimating the effect of common currencies on trade. Economic Policy 30, 7-33.

Rose, A., and Engel, C. 2002. Currency unions and international integration. Journal of Money, Credit and Banking 34, 1067-1089.

Rose, A. K., and Spiegel, M. M. 2009. Cross-Country Causes and Consequences of the 2008 Crisis: Early Warning. CEPR Discussion Paper 7354.

Rua, A. 2010. Measuring comovement in the time-frequency space. Journal of Macroeconomics 32, 685-691.

Rua, A., and Nunes, L. C. 2009. International co-movement of stock returns: A wavelet analysis. Journal of Empirical Finance 16(4), 632-639.

Torrence, C., and Compo, G. P. 1998. A practical guide to wavelet analysis. Bulletin of the American Meteorological Society 79, 605-618.

Torrence, C., and Webster, P. 1999. Interdecadal changes in the ESNOM on soon system. Journal of Climate 12, 2679-2690.

Wynne, M. A., and Jahyeong Koo. 2000. Business Cycles under Monetary Union: A Comparison of the EU and US. Economica 67, 347-74.

Zivot, E., Andrews, D., 1992. Further evidence on the great crash, the oil price shock, and the unit root hypothesis. Journal of Business and Economic Statistics 10, 251-270. 
FIGURE 1: INDUSTRIAL PRODUCTION INDICES (LOG-LEVELS)
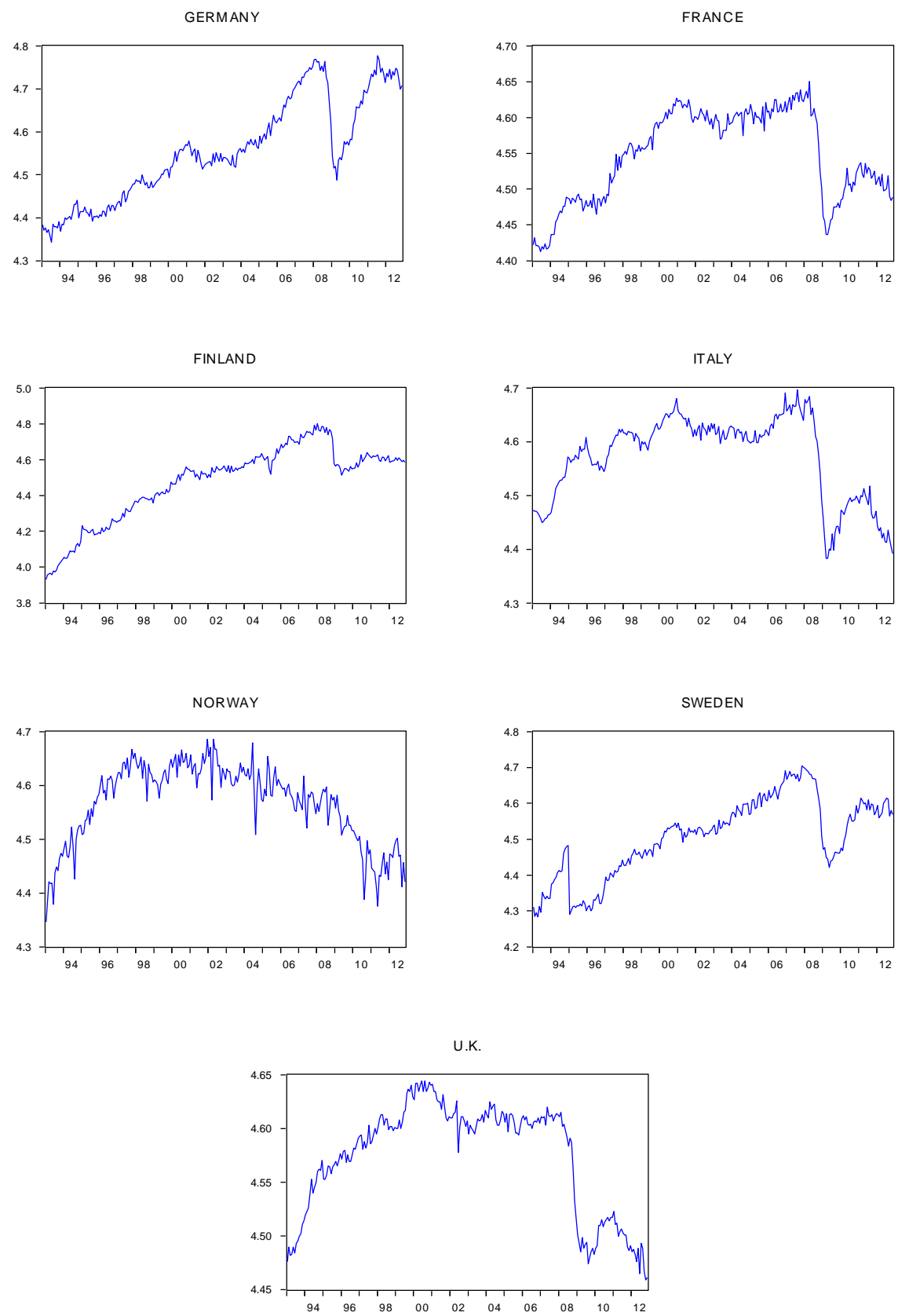

Notes: The time period covered is 1993M01-2012M10. The $x$-axis represents time in years. 

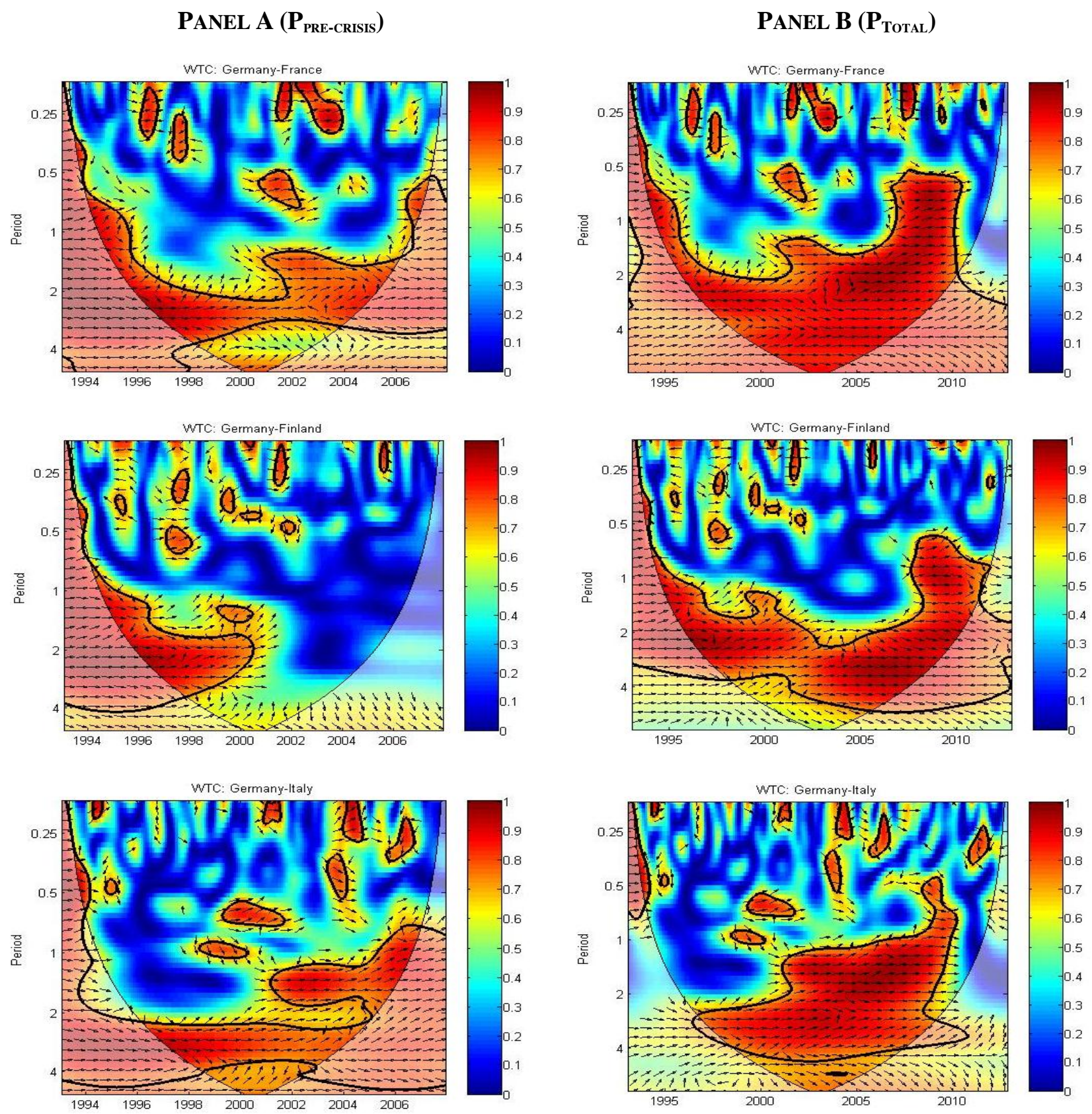

Notes: Phase arrows indicate the direction of co-movement (synchronization) amongst the IP series of Germany vis-àvis Eurozone countries pairwise. The left column (Panel A) of sub-plots depicts the results of cross-wavelet coherence for the pre-crisis period $\left(\mathrm{P}_{\text {pre-crisis }}\right)$, while the right column (Panel B) for the total period $\left(\mathrm{P}_{\text {Total }}\right)$, i.e., including the global financial crisis and the Eurozone debt crisis. Arrows pointing to the right signify perfectly phased variables. The direction "right-up" indicates Germany's lagging business cycle, whilst the "right-down" direction indicates the leading business cycle of Germany vs. the Eurozone countries. Arrows pointing to the left signify out-of-phase variables. The direction "left-up" indicates leading business cycle for Germany, whilst the "left-down" direction indicates a lagging cycle. In-phase variables represent a cyclical relationship and out-of-phase (or anti-phase) variables show anti-cyclical behavior. The thick black contour lines indicate the 5\% significance intervals estimated from Monte Carlo simulations with phase-randomized surrogate series. The cone of influence, which marks the region affected by edge effects, is shown with a lighter shade black line. The color legend for spectrum power ranges from Blue (low power) to Red (high power). Y-axis measures frequency (scale) and X-axis represents the time period studied in years. The corresponding dates are shown in the $\mathrm{X}$-axis. 

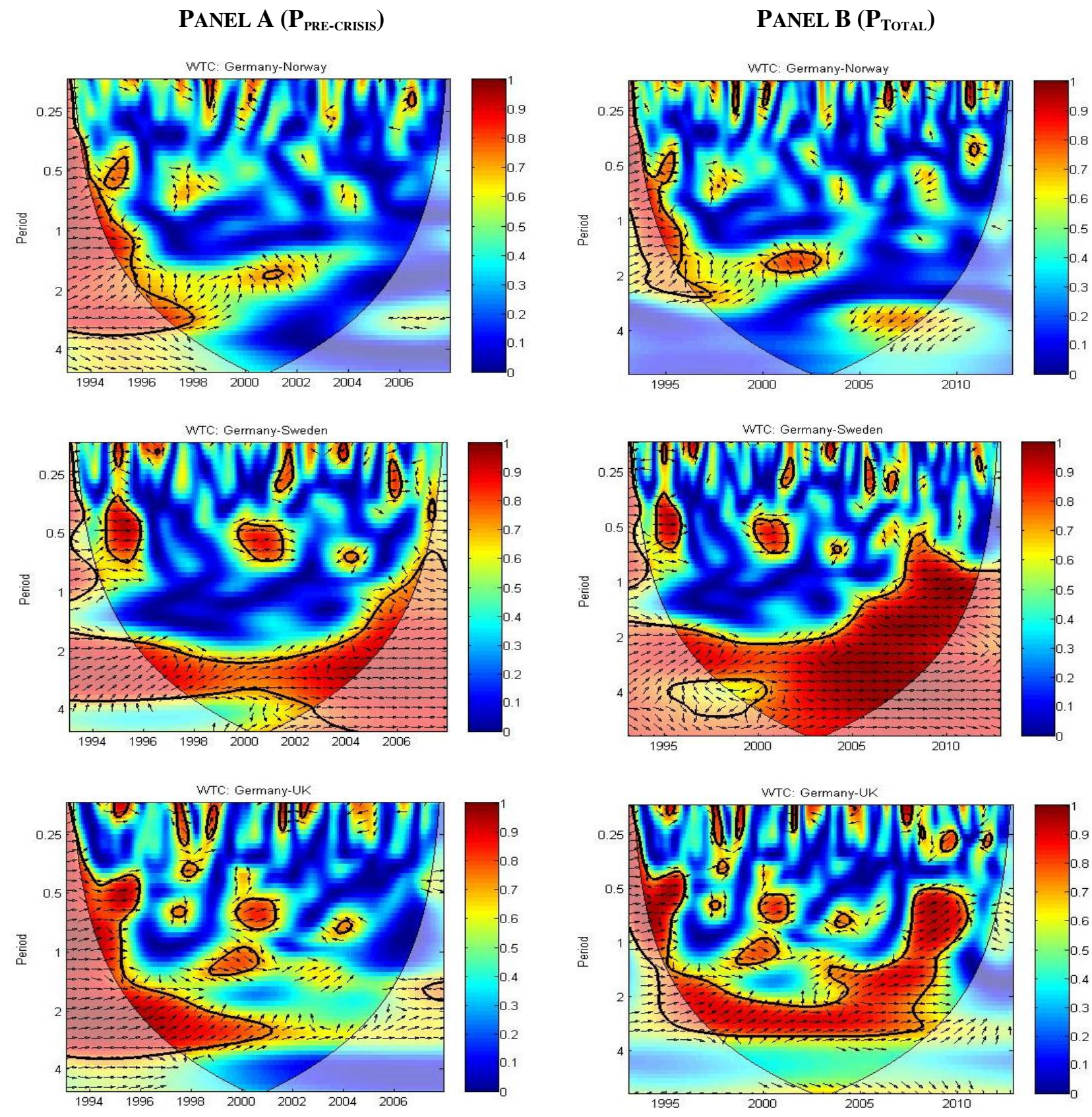

Notes: Phase arrows indicate the direction of co-movement (synchronization) amongst the IP series of Germany vis-àvis Non-Eurozone (Euro area) countries pairwise. The left column (Panel A) of sub-plots depicts the results of crosswavelet coherence for the pre-crisis period $\left(\mathrm{P}_{\text {pre-crisis }}\right)$, while the right column (Panel $\left.\mathrm{B}\right)$ for the total period $\left(\mathrm{P}_{\text {Total }}\right)$, i.e., including the global financial crisis and the Eurozone debt crisis. Arrows pointing to the right signify perfectly phased variables. The direction "right-up" indicates Germany's lagging business cycle, whilst the "right-down" direction indicates the leading business cycle of Germany vs. outside the Eurozone countries. Arrows pointing to the left signify out-of-phase variables. The direction "left-up" indicates leading business cycle for Germany, whilst the "left-down" direction indicates a lagging cycle. In-phase variables represent a cyclical relationship and out-of-phase (or anti-phase) variables show anti-cyclical behavior. The thick black contour lines indicate the $5 \%$ significance intervals estimated from Monte Carlo simulations with phase-randomized surrogate series. The cone of influence, which marks the region affected by edge effects, is shown with a lighter shade black line. The color legend for spectrum power ranges from Blue (low power) to Red (high power). Y-axis measures frequency (scale) and X-axis represents the time period studied in years. The corresponding dates are shown in the $\mathrm{X}$-axis. 
TABLE 1: DesCRIPTIVE Statistics

\begin{tabular}{|c|c|c|c|c|c|c|c|}
\hline & Germany & France & Finland & Italy & Norway & Sweden & U.K. \\
\hline \multicolumn{8}{|c|}{ Panel A ( $\left.\mathrm{P}_{\text {pre-crisis }}\right):$ 1993M01 - 2012M10 } \\
\hline Mean & 4.56 & 4.55 & 4.47 & 4.57 & 4.57 & 4.51 & 4.57 \\
\hline Std. Dev. & 0.12 & 0.06 & 0.21 & 0.08 & 0.07 & 0.11 & 0.05 \\
\hline Skewness & 0.22 & -0.38 & -0.82 & -0.75 & -0.77 & -0.31 & -0.71 \\
\hline Kurtosis & 1.97 & 1.87 & 2.83 & 2.38 & 2.71 & 2.23 & 2.10 \\
\hline$J-B$ & $12.62^{*}$ & $18.46^{*}$ & $26.80^{*}$ & $26.26^{*}$ & $24.21^{*}$ & $9.72^{*}$ & $28.25^{*}$ \\
\hline$Q(12)$ & $2213.60^{*}$ & $2020.63^{*}$ & $2310.73^{*}$ & $1749.26^{*}$ & $1736.23^{*}$ & $2081.23^{*}$ & $2011.76^{*}$ \\
\hline$A R C H(12)$ & $956.44^{*}$ & $414.84^{*}$ & $1121.10^{*}$ & $510.21^{*}$ & $115.00^{*}$ & $430.60^{*}$ & $590.99^{*}$ \\
\hline \multicolumn{8}{|c|}{ Panel B $\left(\mathrm{P}_{\text {Total }}\right): 1993 \mathrm{M} 01-2010 \mathrm{M} 12$} \\
\hline Mean & 4.52 & 4.56 & 4.42 & 4.60 & 4.59 & 4.49 & 4.59 \\
\hline Std. Dev. & 0.10 & 0.06 & 0.22 & 0.05 & 0.06 & 0.11 & 0.04 \\
\hline Skewness & 0.49 & -0.77 & -0.49 & -1.22 & -1.43 & -0.11 & -1.45 \\
\hline Kurtosis & 2.63 & 2.22 & 2.30 & 4.17 & 4.93 & 2.05 & 4.90 \\
\hline$J-B$ & $8.24^{* *}$ & $22.14^{*}$ & $11.04^{*}$ & $54.85^{*}$ & $89.16^{*}$ & $7.10^{* *}$ & $89.94^{*}$ \\
\hline$Q(12)$ & $1581.15^{*}$ & $1663.43^{*}$ & $1653.88^{*}$ & $1277.61^{*}$ & $1043.91^{*}$ & $1576.91^{*}$ & $1310.40^{*}$ \\
\hline$A R C H(12)$ & $912.52^{*}$ & $411.76^{*}$ & $1139.30^{*}$ & $157.85^{*}$ & $40.45^{*}$ & $347.97^{*}$ & $155.89^{*}$ \\
\hline
\end{tabular}

Notes: J-B, $Q^{2}(12)$ and $\mathrm{ARCH}(12)$ symbols correspond respectively to Jarque-Bera normality test, Ljung-Box statistic for 12-order serial autocorrelation squared returns and Engle (1982)'s test for conditional heteroscedasticity. The notation ${ }^{*},{ }^{* *}$, and ${ }^{* * *}$ indicates rejection of the null hypotheses at the $1 \%, 5 \%$ and $10 \%$ level.

Sample segmentation: $\mathrm{P}_{\text {pre-crisis }}$ : 1993M01-2007M12; $\mathrm{P}_{\text {Total }}$ : 1993M01-2012M10. 
TABLE 2: UNIT ROOT TESTS

\begin{tabular}{|c|c|c|c|c|c|c|c|c|}
\hline & \multicolumn{2}{|c|}{ ADF test } & \multicolumn{2}{|c|}{ Phillips-Perron test } & \multicolumn{4}{|c|}{ Zivot-Andrews test } \\
\hline & $A D F(\mu)$ & $A D F(\tau)$ & $P P(\mu)$ & $P P(\tau)$ & $Z A(\mu)$ & Time Break & $Z A(\tau)$ & Time Break \\
\hline \multicolumn{9}{|c|}{ Panel A ( $\left.\mathrm{P}_{\text {pre-crisis }}\right):$ 1993M01 - 2012M10 } \\
\hline Germany & $-1.65(3)$ & $-3.29(3)^{* * * *}$ & $-1.30(7)$ & $-3.00(7)$ & $-5.02(4)^{*}$ & 2008M09 & $-5.65(4)^{*}$ & 2008M09 \\
\hline France & $-1.71(1)$ & $-1.09(1)$ & $-2.76(0)^{* * *}$ & $-1.71(1)$ & $-5.33(2)^{*}$ & 2008M11 & $-4.54(2)^{*}$ & 2008M11 \\
\hline Finland & $-2.90(1)^{* *}$ & $1.49(1)$ & $-2.76(3)^{* * *}$ & $-1.71(3)$ & $-5.33(2)^{*}$ & 2008M11 & $-5.54(2) *$ & 2008M11 \\
\hline Italy & $-1.36(3)$ & $-1.74(3)$ & $-1.31(8)$ & $-1.58(8)$ & $-5.39(4)^{*}$ & 2008M05 & $-5.24(4)^{*}$ & 2008M05 \\
\hline Norway & $-1.56(4)$ & $-2.59(4)$ & $-3.01(7)^{* *}$ & $-3.54(10)^{* *}$ & $-3.55(4)^{*}$ & 2009M03 & $-3.20(4)^{*}$ & 2009M03 \\
\hline Sweden & $-1.98(1)$ & $-2.28(0)$ & $-1.93(3)$ & $-2.24(4)^{*}$ & $-5.45(0)^{*}$ & 2008M09 & $-5.52(0)^{*}$ & 2008M09 \\
\hline$U . K$. & $-0.60(1)$ & $-1.53(1)$ & $-0.96(3)$ & $-1.79(3)$ & $-4.01(1)^{*}$ & 2008M10 & $-3.55(1)^{*}$ & 2008M10 \\
\hline \multicolumn{9}{|c|}{ Panel B $\left(\mathrm{P}_{\text {Total }}\right): 1993 \mathrm{M} 01-2010 \mathrm{M} 12$} \\
\hline Germany & $1.59(2)$ & $-0.51(2)$ & $1.10(7)$ & $-1.99(5)$ & $-2.20(4)^{*}$ & 2005M09 & $-3.10(2)^{*}$ & 2001M09 \\
\hline France & $-1.96(2)$ & $-1.36(2)$ & $-1.86(3)$ & $-2.05(5)$ & $-3.41(2)^{*}$ & 1997M04 & $-3.72(2)^{*}$ & 2001M09 \\
\hline Finland & $-1.94(2)$ & $-2.54(2)$ & $-2.18(12)$ & $-3.09(2)$ & $-3.55(2)^{*}$ & 2001M04 & $-3.63(2)^{*}$ & 2001M04 \\
\hline Italy & $-2.37(1)$ & $-2.21(1)$ & $-2.38(0)$ & $-2.24(2)$ & $-3.19(3)^{* *}$ & 2001M01 & $-3.36(3)^{*}$ & 2001M01 \\
\hline Norway & $-3.72(4)^{*}$ & $-2.55(4)$ & $-4.19(2)^{*}$ & $-4.00(1)^{*}$ & $-3.44(4)$ & 1997M04 & $-3.50(4)$ & 1995M09 \\
\hline Sweden & $-1.05(0)^{*}$ & $-4.08(0)^{*}$ & $-0.64(9)$ & $-3.90(3)^{* *}$ & $-4.45(0)$ & 1995M09 & $-5.06(0)^{*}$ & 1996M11 \\
\hline$U . K$. & $-3.78(2)^{*}$ & $-2.70(2)$ & $-3.79(22)^{*}$ & $-2.81(16)$ & $-3.66(2)^{* *}$ & 2001M02 & $-3.95(2)^{*}$ & 2001M02 \\
\hline
\end{tabular}

Notes: $A D F(\mu), P P(\mu)$ and $Z A(\mu)$ represent the most general model with intercept. $A D F(\tau), P P(\tau)$ and $Z A(\tau)$ is the model with a with constant, constant and trend. The superscripts ${ }^{*},{ }^{* *}$, and ${ }^{* * *}$ indicate the rejection of the null hypotheses at the 1\%,5\% and 10\% levels, respectively. Figures in parenthesis indicate the selected lag length.

Sample segmentation: $\mathrm{P}_{\text {pre-crisis }}$ : 1993M01-2007M12; $\mathrm{P}_{\text {Total }}$ : 1993M01-2012M10. 
TABLE 3: UNCONDITIONAL CORRELATION MATRIX

\begin{tabular}{|c|c|c|c|c|c|c|c|}
\hline & Germany & France & Finland & Italy & Norway & Sweden & U.K. \\
\hline \multicolumn{8}{|c|}{ Panel A $\left(\mathrm{P}_{\text {pre-crisis }}\right): 1993 \mathrm{M} 01-2012 \mathrm{M} 10$} \\
\hline Germany & 1 & & & & & & \\
\hline France & 0.51 & 1 & & & & & \\
\hline Finland & 0.89 & 0.72 & 1 & & & & \\
\hline Italy & 0.07 & 0.82 & 0.30 & 1 & & & \\
\hline Norway & -0.16 & 0.63 & 0.21 & 0.75 & 1 & & \\
\hline Sweden & 0.90 & 0.73 & 0.91 & 0.33 & 0.09 & 1 & \\
\hline$U . K$. & -0.06 & 0.79 & 0.23 & 0.95 & 0.84 & 0.25 & 1 \\
\hline \multicolumn{8}{|c|}{ Panel B $\left(\mathrm{P}_{\text {Total }}\right): 1993 \mathrm{M} 01-2010 \mathrm{M} 12$} \\
\hline Germany & 1 & & & & & & \\
\hline France & 0.87 & 1 & & & & & \\
\hline Finland & 0.94 & 0.96 & 1 & & & & \\
\hline Italy & 0.79 & 0.91 & 0.88 & 1 & & & \\
\hline Norway & 0.36 & 0.67 & 0.59 & 0.74 & 1 & & \\
\hline Sweden & 0.95 & 0.88 & 0.92 & 0.74 & 0.37 & 1 & \\
\hline$U . K$. & 0.65 & 0.88 & 0.81 & 0.91 & 0.84 & 0.66 & 1 \\
\hline
\end{tabular}

Notes: The sample segmentation is $\mathrm{P}_{\text {pre-crisis }}$ : 1993M01-2007M12 and $\mathrm{P}_{\text {Total }}$ : 1993M01-2012M10. 